\title{
Fear of losing in a clock auction
}

\author{
Peter Cramton • Emel Filiz-Ozbay • \\ Erkut Y. Ozbay • Pacharasut Sujarittanonta
}

Received: 19 November 2011 / Accepted: 23 April 2012 / Published online: 26 May 2012

(C) Springer-Verlag 2012

\begin{abstract}
We examine bidding behavior in a clock auction in which price is set by the lowest-accepted bid and provisional winners are reported each round (the LABpw auction). This format was used in the India $3 \mathrm{G}$ spectrum auction. In the standard theory, the auction performs poorly. In particular it yields lower revenues and is less efficient than the more standard clock auction with exit bids and highest-rejected-bid pricing (the HRB auction). However, the LABpw auction performs well in the lab, achieving higher revenues than the HRB auction. We show how fear of losing provides one motivation for the overbidding that causes higher revenues in the LABpw auction.
\end{abstract}

Keywords Clock auction · Regret $\cdot$ Lowest accepted bid $\cdot$ Provisional winner

JEL Classification $\quad$ D44 $\cdot$ C78 $\cdot$ L96

\section{Introduction}

In 2010, the India government conducted an auction for its $3 \mathrm{G}$ spectrum. It was one of the first spectrum auctions to apply lowest-accepted bid as a pricing rule in a clock auction. Lowest-accepted bid pricing has been used predominantly in simultaneous ascending spectrum auctions such as Canada AWS, US AWS-1, US $700 \mathrm{MHz}$ and Germany 4G auctions. The clock auction is usually implemented with highest-rejected bid pricing. In practice, a discrete clock is used in order to simplify the communication

We thank our colleagues, Lawrence M. Ausubel and Daniel R. Vincent, for helpful discussions. We thank the National Science Foundation for support.

P. Cramton · E. Filiz-Ozbay · E. Y. Ozbay $(\varangle) \cdot$ P. Sujarittanonta

Department of Economics, University of Maryland, College Park, MD, USA

e-mail: erkut.ozbay@gmail.com 
process and mitigate tacit collusion (Ausubel and Cramton 2004). The combination of a clock auction with lowest-accepted bid pricing is the focus of this paper.

In the India 3G auction, the lowest-accepted bid pricing rule was used in conjunction with a provisional winner designation. We call this auction lowest-accepted bid with provisional winner (the LABpw auction). In theory, the LABpw auction yields an inefficient allocation and lower expected revenue than the efficient auction, which lets the highest-rejected bid set the price (Cramton and Sujarittanonta 2010). Nevertheless, the India 3G spectrum auction was regarded as a great success in terms of revenue. The auction generated $\$ 11$ billion in revenue whereas the India government expected to get merely $\$ 7.5$ billion (Kinetz 2010).

The India $3 \mathrm{G}$ auction outcome provides some evidence to question the theoretical finding of lower revenue. But only a single empirical outcome is inadequate to draw any conclusions about the revenue properties of the LABpw auction. The purpose of this paper is to provide experimental evidence about the properties of the LABpw auction.

We study revenue, efficiency and bidding behavior of the LABpw auction in the lab. In our experiment, we find that the LABpw auction yields higher revenue than the theoretical prediction, consistent with the apparent revenue observation from the India $3 \mathrm{G}$ spectrum auction. The experimental design enables us to compare the LABpw auction to the efficient auction data from another experiment (Cramton et al. 2012). We find that the LABpw auction generates greater revenue but lower efficiency than the efficient auction. As standard theory fails to explain the revenue of the LABpw auction, we then propose a fear of losing model that is consistent with our experimental finding.

In Sect. 2, we outline a theoretical model of the LABpw auction. Section 3 provides the experimental method. We summarize the experimental result and compare the LABpw auction to the efficient auction in Sects. 4 and 5, respectively. We present a modified model of LABpw that can explain the experimental outcome in Sect. 6.

\section{Model of the LABpw auction}

There is one indivisible good for sale to two risk neutral bidders. ${ }^{1}$ Bidder $i$ 's private value for the good is $v_{i}$ where each $v_{i}$ is independently drawn from uniform distribution on the interval $[50,100]$. Bidder $i$ 's payoff if she wins the good at a price $p$ is $v_{i}-p$. Otherwise, it is equal to 0 . The seller values the good at 0 .

Before the auction starts, the seller announces six bid levels, $P=(50,60,70,80$, $90,100)$ where 50 is the reserve price. The clock price starts at 60 and increases every round to the next bid level until the auction ends. In every round, bidders decide whether to stay in at the current clock price or to exit. Once a bidder exits, she cannot bid again. At the beginning of each round, one of the active bidders-bidders who stayed in at the previous clock price-is randomly selected as the provisional winner

\footnotetext{
${ }^{1}$ For $\mathrm{N}>2$, the main theoretical result is still true: HRB is efficient but LABpw is inefficient. The strategy of provisional losers in LABpw are also unaffected by the number of bidders. The closed form solution of LABpw (see Proposition 1) is history dependent. Although it is possible to calculate the strategies, it will add unnecessary notation.
} 
Table 1 Provisional winner's equilibrium strategy for the LABpw auction

${ }^{a}$ History vector denotes whether the bidder is a provisional winner (W) or not (L) in from the first round up to the current round

${ }^{\mathrm{b}}$ Critical valuation is the threshold such that the bidder stays in if her value is above the corresponding threshold

\begin{tabular}{llc}
\hline Round & History $^{\mathrm{a}}$ & Critical valuation $^{\mathrm{b}}$ \\
\hline 1 & $(\mathrm{~W})$ & 74 \\
2 & $(\mathrm{~W}, \mathrm{~W})$ & 84 \\
& $(\mathrm{~L}, \mathrm{~W})$ & 70 \\
3 & $(\mathrm{~W}, \mathrm{~W}, \mathrm{~W})$ and $(\mathrm{W}, \mathrm{L}, \mathrm{W})$ & 94 \\
& $(\mathrm{~L}, \mathrm{~W}, \mathrm{~W})$ & 90.8 \\
& $(\mathrm{~L}, \mathrm{~L}, \mathrm{~W})$ & 80 \\
4 & (W,L,L,W), (L,W,L,W) and (L,L,L,W) & 90 \\
& Otherwise & 100 \\
5 & Any & 100 \\
\hline
\end{tabular}

of that round. Both bidders are active at the reserve price by default. If both bidders stay in, the auction proceeds to the next round. If only one bidder exits and the other stays in, the bidder who stayed in wins the good and pays the current clock price. If both bidders exit, the provisional winner of that round wins the good and pays the previous clock price. If both bidders stay in round 5, the good is randomly awarded to one of the bidders. ${ }^{2}$

We set the price increments and the number of rounds close to those in actual auctions. We have a maximum of five rounds in our model, and the price increments are $10-20 \%$ of the current price in each round. For example in diamond auctions for large stones, typically there are 4-6 rounds and increments are 10-20\% of the price range. In $3 \mathrm{G}$ auction in India, if there is one bidder more than the number of spectrum slots, the price increment was $5 \%$ of the current price and if there are two bidders more than the available slots, then the current price was raised by $10 \%$.

Proposition 1 In a perfect Bayesian equilibrium of the LABpw auction, the provisional loser stays in provided her value is not yet reached; the provisional winner exits at a level below her value (see Table 1 for the precise strategy of the bidders given the parameters used in the model).

The intuition of the characterization is as follows: If the provisional loser stays out, she will lose the auction. Therefore, it is a weakly dominant strategy for her to stay in if the price is less than her value. On the other hand, the provisional winner faces a rather difficult decision. Since the pricing rule is to pay the price level she stayed in, as in first price sealed bid auction, the distribution of the other bidder plays a role. Depending on the history, the provisional winner will update the belief on the distribution of the other bidder's signal and she decides whether to stay in if the expected value of staying in is higher than staying out. For example, the provisional winner (with a value of $v$ ) at $P=80$ with history of $(\mathrm{W}, \mathrm{W}, \mathrm{W}, \mathrm{W})$ updates that the other bidder's value is in $[80,100]$ and at $P=90$, the other bidder stays in only if her value is more than 90 . Hence, if the provisional winner at $P=80$ stays out, she wins if the value of the other

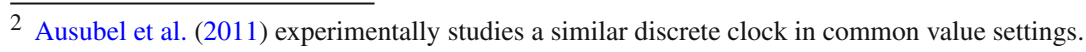


bidder is in $[80,90]$, the probability of this event is $1 / 2$. Therefore, her expected payoff from staying out is $1 / 2(v-80)$. On the other hand if she stays in then she wins when the other bidder's value is in $[80,90]$ and when the other bidder's value is $[90,100]$ and she becomes the provisional winner at $P=90$ (since all bidders with a value less than 100 must stay out at $P=100)$. Therefore, her expected payoff from staying in is $3 / 4(v-90)$. Hence for any value, it is optimal to stay out.

\section{Proposition 2 The outcome is inefficient and does not maximize seller revenue.}

There are two sources of inefficiency in the LABpw auction. First, there is no precise value information to determine who has the higher value among the two bidders who exit in the same round. For example, consider bidders 1 and 2 whose values are 53 and 59, respectively. Assume that bidder 1 is the provisional winner in round 1. According to Table 1, both will exit in the first round. Bidder 1 whose value is less than bidder 2 wins and the outcome is inefficient. If there were finer bid levels (e.g. 50, 55, 60, .., 100), bidder 2 would have stayed in at 55 and won. Second, the provisional winner designation ex ante creates differential bid shading-provisional winners shade bids while provisional losers with the same value bid their values. For example, a bidder with value of 65 will drop out if she is a provisional winner and stay in otherwise. Since in our setting there is no conflict between efficiency and revenue maximization - the efficient auction maximizes revenues - the LABpw auction does not maximize seller revenue.

\section{Experimental method}

The experiments were run at the Experimental Economics Lab at the University of Maryland. All participants were undergraduate students at the University of Maryland. The experiment involved two sessions with 16 and 14 subjects. No subject participated in more than one session. Participants were seated in isolated booths. Each session lasted about $80 \mathrm{~min}$. Bidder instructions are in the "Appendix". To test the subjects' understanding of the instructions, they had to answer a sequence of multiple choice questions. The auctions did not begin until each subject answered all of the multiple choice questions correctly.

In each session, each subject participated in 21 auctions. The first auction was a practice auction. Each auction had two randomly matched bidders. Bidders were randomly rematched after each auction. All bidding was anonymous. Bids were entered via computer. The experiment is programmed in $z$-Tree (Fischbacher 2007). At the conclusion of each auction, the bidder learned whether she won and the price paid by the winning bidder.

The parameters that were studied in the previous section were used in the experiment. Hence, in each LABpw auction, each bidder received a private value from uniform distribution from [50,100], independently and there were six bid levels with price increments of 10 . The entire history of provisional winners was shown on the bidding screen for the auction.

The winner in each auction earned her value minus the price paid in experimental currency units (ECU). At the end of the experiment, total earnings were converted to 


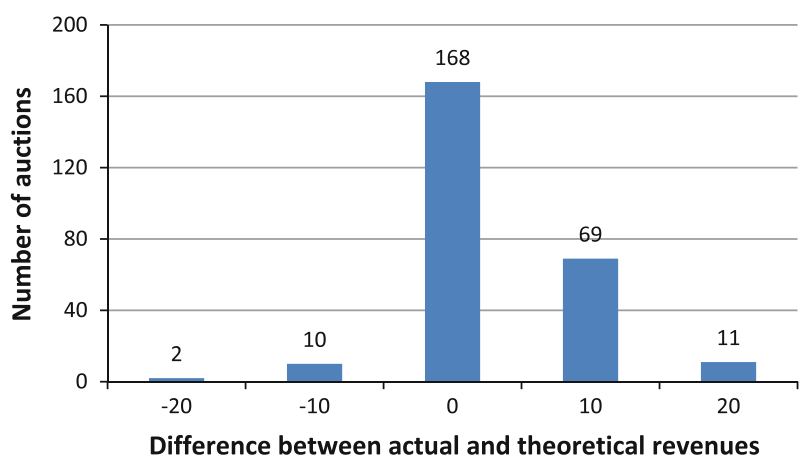

Fig. 1 Difference between actual and theoretical revenues

US Dollars, at the conversion rate of $10 \mathrm{ECU}=1 \mathrm{US}$ Dollar. Subjects also received a $\$ 5$ show-up fee. Cash payments were made at the conclusion of the experiment. The average subject payment was $\$ 23.96$.

\section{Experimental results}

The experiment consists of 300 auctions. Figure 1 shows a histogram of difference between actual and theoretical revenues. A large number of auctions generate higher revenue than expected. The actual average revenue from the experiment is 69.33 per auction while the theory predicts 65.87 per auction given the value draws used in the experiment. With Wilcoxon-Mann-Whitney test, the actual revenue is significantly different than the theoretical revenue $(z=4.17, p<0.01)$. LABpw pricing rule is similar to first-price auction rule since in both formats the highest bid that clears the market is the price. The experimental literature robustly finds higher bids in a firstprice auction compared to the risk-neutral Nash equilibrium prediction (see Cox et al. 1982, 1988; Kagel and Levin 1993 as the seminal papers; Kagel 1995; Kagel and Levin 2008 for detailed surveys). ${ }^{3}$

The number of auctions with an inefficient outcome is the same as the theoretical prediction-44 out of 300 auctions are inefficient - although inefficient outcomes in the experiment and theory take place in different instances. Wilcoxon-Mann-Whitney test cannot reject the hypothesis that there is a significant difference between actual and theoretical efficiencies $(z=0.00, p=1.00)$.

A total of 367 exit decisions are observed. A histogram of differences between actual and theoretical exit rounds is shown in Fig. 2. In 91 observations, subjects stayed in for too long while in 33 observations they underbid. Note that Fig. 2 does not include active bidders whose exit decisions have not yet been observed. However, we can conclusively say that 49 out of 233 active bidders have stayed in for too long. This tendency to exit late leads to the actual revenue being higher than predicted.

3 Risk aversion offers one explanation, but this has proven inadequate (see Kagel 1995). Several papers explain the overbidding phenomena with behavioral motives (for example, Delgado et al. 2008; EngelbrechtWiggans and Katok 2008; Filiz-Ozbay and Ozbay 2007, 2010; Lange and Ratan 2010). 


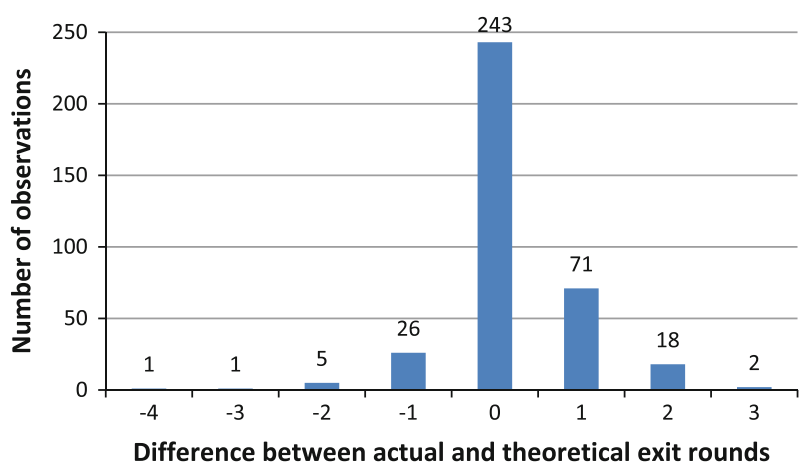

Fig. 2 Difference between actual and theoretical exit rounds

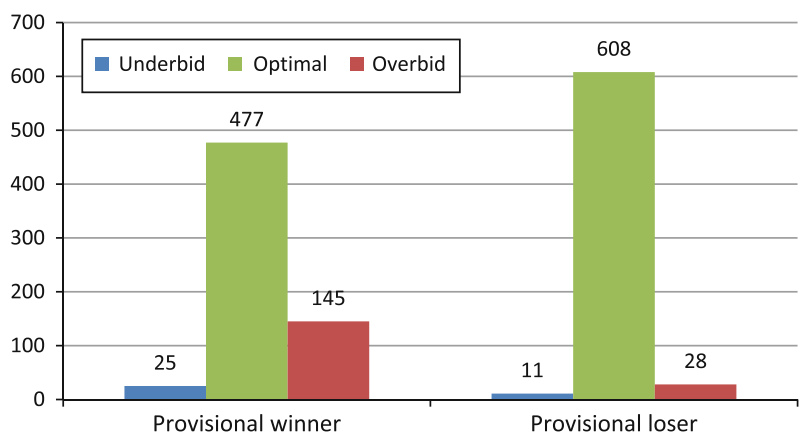

Fig. 3 Bid decisions of provisional winners and losers

Next, we look at bidding behavior of subjects when being selected as provisional winner and loser. We observed 1,294 bid decisions, 647 decisions for provisional winners and losers each. Each bid decision can be categorized into three groups: underbid, optimal and overbid. A decision is optimal if it is the same as the theoretical prediction. A decision is underbid if a subject exits when the theory expects her to bid. A decision is overbid if a subject bids when the theory expects her to exit. Figure 3 shows frequencies of each type of bid decisions. Most overbidding is done by provisional winners. In other words, most provisional winners shade their bids less than theoretical prediction while most provisional losers bid straightforwardly as predicted.

Each subject participates in 20 auctions plus one trial auction. To see the learning effect, we group decisions of four consecutive auctions. Figure $4 \mathrm{a}, \mathrm{b}$ show the percentage of non-optimal bid decisions of provisional winners and losers. For provisional winners, we see a slight downward trend in the percentage of overbidding but there is no obvious evidence of a learning effect. For provisional losers, the percentage of overbidding decreases sharply after the fourth auction and continue to decline afterward.

The slower learning of provisional winners is not surprising. A provisional winner's decision is more complicated than a provisional loser's because of the history dependence. A provisional winner needs to take into account the entire history of 

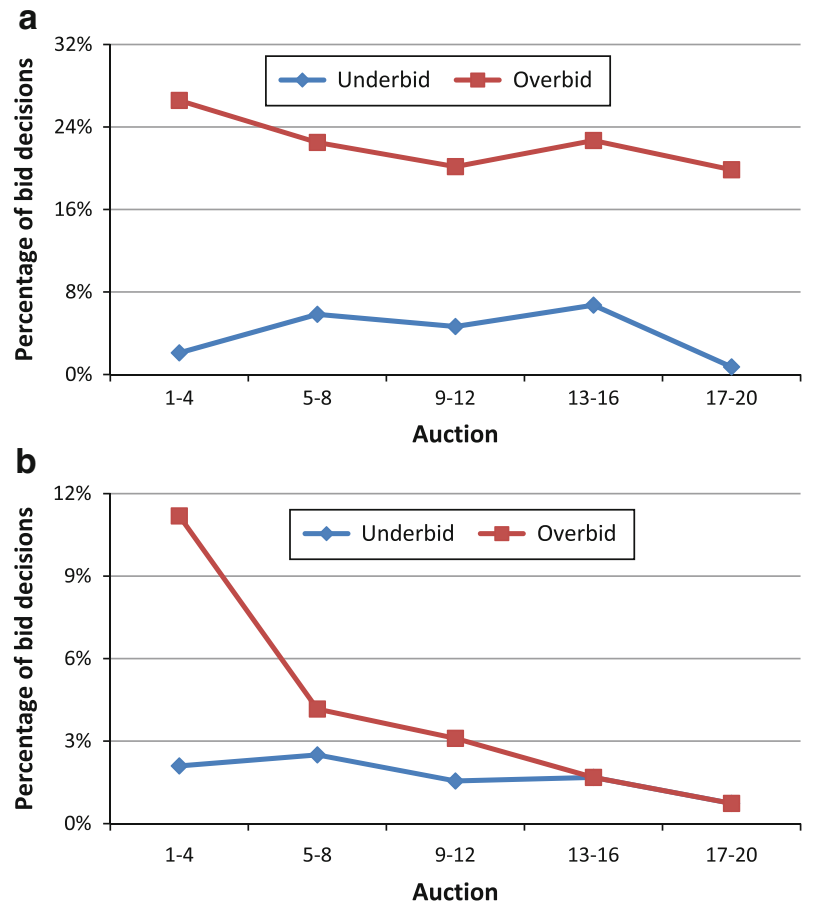

Fig. 4 a Percentage of non-optimal bid decisions of provisional winners. b Percentage of non-optimal bid decisions of provisional losers

provisional winners to make the inference of the opponent's value while a provisional loser does not need to make any inference.

\section{Comparison between LABpw and an efficient auction}

Our theoretical findings on LABpw suggested that an auctioneer who aims to maximize revenue or efficiency in allocation should not use this format. However, the LABpw auction, both in the field and in our experiment, appears to generate high revenue. In this section we will compare LABpw to an ascending clock auction in which bidders bid an exit bid when they drop out and the price is set by the highest rejected bid (HRB auction).

In HRB auction, price levels are commonly known as in LABpw. The clock price starts at the initial level and increases one level as long as there is excess demand at the current price. If a bidder exits at a particular price level, she specifies an exit bid-a price between the previous price and current clock price at which she wants to exit. The bidder who submits the highest bid or exit bid wins the good and pays the losing bid (the highest rejected bid) to the auctioneer.

In contrast to the LABpw auction, HRB auction allows bidder to choose exit bids from a continuous space rather than restricting the bid to a set of permissible bid levels. 
Table 2 Comparison among outcomes of treatment LABpw and HRB

\begin{tabular}{lll}
\hline Variable & LABpw & HRB \\
\hline Value & 74.87 & 75.55 \\
& $(0.61)$ & $(0.59)$ \\
Frequency of efficient allocation & $85.3 \%$ & $92.0 \%$ \\
& $(2.05)$ & $(1.55)$ \\
Revenue per auction & 69.3 & 67.3 \\
& $(0.65)$ & $(0.70)$ \\
Seller's share of theoretical gains from trade & $85.3 \%$ & $80.8 \%$ \\
& $(0.77)$ & $(0.72)$ \\
\hline
\end{tabular}

Standard errors are given in the parentheses

Bidders can fully express their values. Moreover, the pricing rule is equivalent to Vickrey pricing - the winner pays the social opportunity cost. The dominant strategy equilibrium bidding strategy is to bid one's value, and thus the outcome is efficient.

Next, we compare our findings to those in our earlier paper (Cramton et al. 2012) which experimentally tested the HRB auction with identical parameters as the experiment presented here.

Table 2 compares outcomes from LABpw and HRB auctions. 92 and $85.3 \%$ of HRB and LABpw auctions, respectively, yield the efficient allocation. With Wilcoxon-Mann-Whitney test, the LABpw auction's frequency of efficiency is significantly different from the HRB auction $(z=2.57, p=0.01)$.

According to Table 2, treatment LABpw yields higher revenues (price paid by the winner) than HRB in average. The values in Table 2 are the average value draws of the bidders in two treatments. In order to take into account the random value draws, we will use the seller's share of the theoretical gains from trade (the ratio of the actual final price and the value of the bidder who is predicted to be the winner by the theory) as the proxy for the revenues. This measures how much the seller gained from the value that would have been generated if the bidder predicted by the theory won. With Wilcoxon-Mann-Whitney test, LABpw and HRB generate significantly different seller shares $(z=3.52, p<0.01)$.

Figure 5 compares actual, and theoretical seller's share of the gains from trade per auction. Theoretical seller's share is the equilibrium seller's share given the realization of valuations. The actual seller's share of HRB is slightly higher than the theoretical one, but actual seller's share of LAB and LABpw are significantly higher than the theoretical prediction.

\section{Theory with fear of losing}

Bid shading in LABpw may lead to a situation where a bidder finds herself losing at an affordable price. For example, consider a provisional winner at price level $\$ 70$, with a valuation of $\$ 84$. If she exits at $\$ 70$ and her opponent stays in at $\$ 70$, the provisional winner loses at an affordable level. However, it is not clear how the outcome 


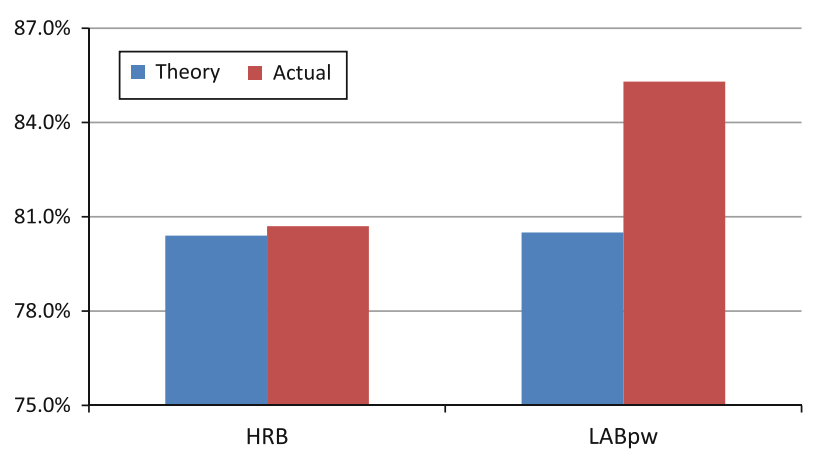

Fig. 5 Actual and theoretical seller shares of gains from trade

would have changed if she had stayed in since she cannot infer the price at which her opponent would exit. Regardless, she can at most imagine some events in which she would be better off if she did not exit at $\$ 70$. One of those events is that at a price level of $\$ 70$ both bidders stay in and at a price level of $\$ 80$ her opponent exits. In such an event, the provisional winner would make positive profit. A bidder who fears losing and experiencing such situations as in the example above will shade her bid less than a bidder focused solely on profit maximization. LABpw may achieve higher revenues if bidders fear losing.

This type of regret, loser regret, has been shown to explain overbidding in first-price sealed-bid auctions (Filiz-Ozbay and Ozbay 2007; Engelbrecht-Wiggans and Katok 2008). ${ }^{4}$ Filiz-Ozbay and Ozbay (2007) provide experimental evidence that subjects anticipate loser regret and reflect this to their bids. The source of loser regret in firstprice auctions is defined to be the difference between the bidder's value and the winning bid whenever the winning bid is affordable. In contrast to the first-price auction, in dynamic auctions it may be unclear for a losing bidder how the outcome would change if she bid differently. Therefore, ex-post a losing bidder may only regret in expectation. Kőszegi and Rabin (2006) provide a model of reference-dependent preferences and loss aversion where the reference point can be stochastic (see also Sugden 2003). In our setting, the outcome of alternative actions of a bidder may serve as the stochastic reference point, ${ }^{5}$ and hence the loser regret in expectation as a source of fear of losing can be incorporated into dynamic auctions with the model of Köszegi and Rabin (2006).

As in Kőszegi and Rabin (2006), we define the utility of a bidder when the auction outcome is $c$ and the reference outcome is $r$ as

$$
u(c \mid r)=m(c)-\alpha \max \{0, m(r)-m(c)\}
$$

where $m$ is the consumption utility. The first term captures the monetary utility of the outcome. It is $v_{i}-p$ if bidder $i$ wins at price $p$ and zero otherwise. The second term

\footnotetext{
4 Also, Filiz-Ozbay and Ozbay (2010) study regret in third price auctions.

5 In the first-price sealed bid auctions, the winning bid is the reference point for modeling regret.
} 
compares the actual monetary utility with the reference monetary utility and if the latter is higher, the difference is a disutility. $\alpha \geq 0$ is bidder's fear of losing coefficient which can be motivated by regret in our setting. Any bid history in a dynamic auction generates the distribution $(F)$ of consumption level and the distribution $(G)$ of the reference point. Hence, as in Kőszegi and Rabin (2006), the expected utility of a bidder after any history can be represented as:

$$
U(F \mid G)=\iint u(c \mid r) d G(r) d F(c)
$$

Appendix A provides an explicit reference dependent expected utility calculation in our setup.

Filiz-Ozbay and Ozbay (2007) show that only the losers but not the winners engage in negative emotion. Therefore, in the formulation we use, the reference outcome for a winner will be the outcome of the auction and the utility will be only the consumption utility.

Table 3 Equilibrium strategy for the LABpw auction with $\alpha \geq 0$

\begin{tabular}{|c|c|c|c|}
\hline \multirow[t]{2}{*}{ Round } & \multirow[t]{2}{*}{ History $^{\mathrm{a}}$} & \multicolumn{2}{|l|}{ Critical valuation ${ }^{\mathrm{b}}$} \\
\hline & & $0 \leq \alpha<1$ & $\alpha \geq 1$ \\
\hline 1 & (W) & $70+4 \cdot \frac{1-\alpha}{1+\alpha}$ & $60+\frac{20}{1+\alpha}$ \\
\hline \multirow[t]{2}{*}{2} & $(\mathrm{~W}, \mathrm{~W})$ & $80+4 \cdot \frac{1-\alpha}{1+\alpha}$ & $70+\frac{20}{1+\alpha}$ \\
\hline & $(\mathrm{L}, \mathrm{W})$ & 70 & $80+\frac{20(\alpha-1)}{(1+\alpha)^{2}}$ \\
\hline \multirow[t]{4}{*}{3} & $(\mathrm{~W}, \mathrm{~W}, \mathrm{~W})$ & $90+4 \cdot \frac{1-\alpha}{1+\alpha}$ & $80+\frac{20}{1+\alpha}$ \\
\hline & $(\mathrm{W}, \mathrm{L}, \mathrm{W})$ & $90+4 \cdot \frac{1-\alpha}{1+\alpha}$ & $80+\frac{20\left(3+\alpha^{2}\right)}{(1+\alpha)^{3}}$ \\
\hline & $(\mathrm{L}, \mathrm{W}, \mathrm{W})$ & $90+\frac{4(1+5 \alpha)(1-\alpha)}{5(1+\alpha)^{2}}$ & $80+\frac{20}{1+\alpha}$ \\
\hline & $(\mathrm{L}, \mathrm{L}, \mathrm{W})$ & 80 & $80+\frac{20(\alpha-1)}{(1+\alpha)^{2}}$ \\
\hline \multirow[t]{8}{*}{4} & $(\mathrm{~W}, \mathrm{~W}, \mathrm{~W}, \mathrm{~W})$ & 100 & $90+\frac{20}{1+\alpha}$ \\
\hline & $(\mathrm{W}, \mathrm{W}, \mathrm{L}, \mathrm{W})$ & 100 & $90+\frac{20\left(3+\alpha^{2}\right)}{(1+\alpha)^{3}}$ \\
\hline & $(\mathrm{W}, \mathrm{L}, \mathrm{W}, \mathrm{W})$ & 100 & $90+\frac{20}{1+\alpha}$ \\
\hline & $(\mathrm{W}, \mathrm{L}, \mathrm{L}, \mathrm{W})$ & 90 & $90+\frac{20(\alpha-1)}{(1+\alpha)^{2}}$ \\
\hline & $(\mathrm{L}, \mathrm{W}, \mathrm{W}, \mathrm{W})$ & 100 & $90+\frac{20}{1+\alpha}$ \\
\hline & $(\mathrm{L}, \mathrm{W}, \mathrm{L}, \mathrm{W})$ & 90 & $90+\frac{20\left(\alpha\left(3+\alpha+\alpha^{2}\right)-5\right)}{4}$ \\
\hline & $(\mathrm{L}, \mathrm{L}, \mathrm{W}, \mathrm{W})$ & 100 & $90+\frac{20}{1+\alpha}^{(1+\alpha)^{4}}$ \\
\hline & $(\mathrm{L}, \mathrm{L}, \mathrm{L}, \mathrm{W})$ & 90 & $90+\frac{20(\alpha-1)}{\alpha(1))^{2}}$ \\
\hline 5 & Any & 100 & $100^{(1+\alpha)^{2}}$ \\
\hline
\end{tabular}

${ }^{a}$ History vector denotes whether the bidder is a provisional winner (W) or not (L) in all the rounds up to the current round

${ }^{\mathrm{b}}$ Critical valuation denotes the threshold such that the bidder stays in if her value is above the corresponding threshold 


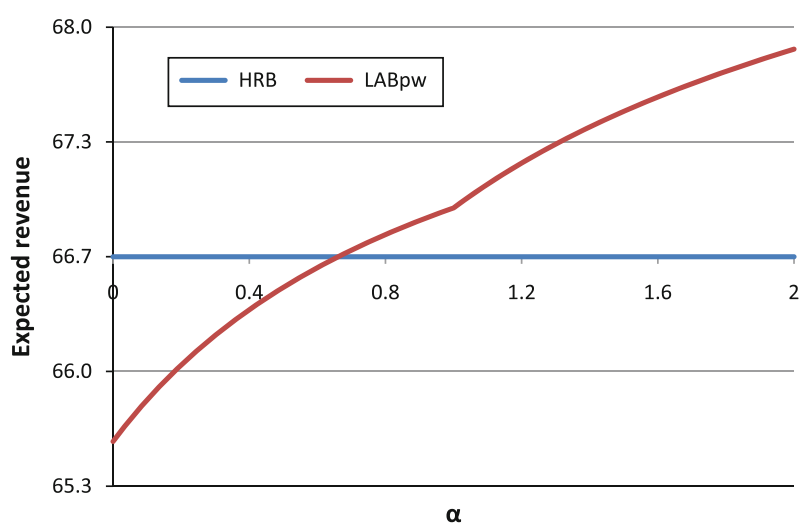

Fig. 6 Revenue of LABpw as a function of $\alpha$

Proposition 6 In a perfect Bayesian equilibrium of the LABpw auction with fear of losing, the provisional loser stays in provided her value is not yet reached; the provisional winner exits at a level below her true value (see Table 3). The exit level depends on the provisional winning history. Moreover, the outcome is inefficient.

Remark Revenue is strictly increasing in $\alpha$. LABpw revenues are greater than HRB revenues for sufficiently large $\alpha$.

Figure 6 shows how revenue of LABpw depends on the fear of losing coefficient $\alpha$ in our setup with six bid levels. One may also note on the figure that for our parameters and value draws used in the experiment, the revenue the standard theory predicts for HRB format is 66.67. It is easy to show that the equilibrium strategy in HRB is unaffected when we modify the utility as reference dependent utility. Therefore, the expected revenue for HRB is always 66.67 independent of $\alpha$. However, for small $\alpha$, LABpw is expected to generate lower revenue than HRB but this is not true for $\alpha$ greater than 0.66 .

\section{Conclusion}

Based on the standard theory, the LABpw auction would appear to be a poor choice. It is dominated by the HRB auction in both revenues and efficiency. Despite this poor theoretical performance, the India government chose the LABpw auction for the India $3 \mathrm{G}$ auction. Revenue maximization was an important goal of the regulator in this choice. Our analysis of the LABpw auction in the experimental lab suggests that India's choice may not have been a bad one. We find that the LABpw auction yields higher revenues than the HRB auction.

One explanation for the high revenues is fear of losing. The LABpw auction, like a first-price auction, exposes bidders to the possibility that they may lose at a profitable price. Bidders can reduce this possibility by bidding more aggressively. This overbidding results in higher revenues. 


\section{Appendix A}

Let $q_{i t} \in\{0,1\}$ denote the bid of bidder $i$ in round $t$ where 0 means "exiting" and 1 means "staying in" the auction.

\section{Lowest-accepted-bid with provisional winners}

We use the same approach for equilibrium characterization as Cramton and Sujarittanonta (2010). Let $\Pi_{i, t+1}\left(v_{i}, \mathbf{H}_{i t}, \alpha\right)$ be the bidder $i$ 's expected utility if the auction continues to round $t-+1$ where $\mathbf{H}_{i t}$ is a vector of bidder $i$ 's ranking history from round one to round $t$. Let $\hat{v}_{t}\left(\mathbf{H}_{i t}, \alpha\right)$ be a critical valuation such that a bidder with valuation in $\left[\hat{v}_{t}\left(\mathbf{H}_{i t}, \alpha\right), 100\right]$ bids in round $t$ given a ranking history $\mathbf{H}_{i t}$ and a fear of losing coefficient $\alpha$. An equilibrium bidding strategy is specified by critical valuations $\hat{x}_{t}\left(\mathbf{H}_{i t}, \alpha\right)$ for all rounds $t=1, \ldots 5$ and for all possible ranking histories in Table 3 . Since there are two bidders, the opponent's ranking history is a complement of bidder $i$ 's ranking history. In the LABpw auction, when bidder $i$ with $v_{i}$ considers staying in in round $t$, Eq. (1) becomes

$$
\pi_{i t}\left(v_{i}, \mathbf{H}_{i t}, \alpha\right)=\left(v_{i}-P_{t}\right) \frac{P_{t}-\hat{v}_{t}\left(\mathbf{H}_{i t}, \alpha\right)}{1-\hat{v}_{t}\left(\mathbf{H}_{i t}, \alpha\right)}+\Pi_{i, t+1}\left(v_{i}, \mathbf{H}_{i t}, \alpha\right) \frac{1-P_{t}}{1-\hat{v}_{t}\left(\mathbf{H}_{i t}, \alpha\right)}
$$

where the first term is the expected payoff if the opponent exits in round $t$, and the second term is the expected payoff if the opponent stays in in round $t$.

When bidder $i$ with $v_{i}$ considers staying out in round $t$, Eq. (1) becomes

$$
\begin{aligned}
\pi_{i t}\left(v_{i}, \mathbf{H}_{i t}, \alpha\right)= & \left(v_{i}-P_{t-1}\right) \frac{P_{t}-\hat{v}_{t}\left(\mathbf{H}_{i t}, \alpha\right)}{1-\hat{v}_{t}\left(\mathbf{H}_{i t}, \alpha\right)} \\
& -\alpha \max \left\{0, \Pi_{i, t+1}\left(v_{i}, \mathbf{H}_{i t}, \alpha\right) \frac{1-P_{t}}{1-\hat{v}_{t}\left(\mathbf{H}_{i t}, \alpha\right)}\right\}
\end{aligned}
$$

where the first term is the expected payoff if the opponent exits in round $t$, and the second term is the expected disutility if the opponent stays in in round $t$. For example, consider bidder $i$, the provisional winner at price level $\$ 70$, with a valuation of $\$ 84$ exiting at $\$ 70$. If her opponent stays in at $\$ 70$ or at $\$ 80$ and if bidder $i$ loses at $\$ 80$, bidder $i$ will lose at an affordable level. Her expected payoff will be the source of the disutility.

\section{Appendix B}

\section{Experiment instructions for LABpw}

Welcome to the auction experiment. In this experiment, you will participate in auctions as a bidder. The precise rules and procedures that govern the operation of these auctions will be explained to you below. 
Various research foundations have provided funds for this research. The instructions are simple, and if you follow them carefully and make good decisions you can finish the experiment with a considerable amount of money, which will be paid to you in cash at the end. The experiment will last about $80 \mathrm{~min}$.

The type of currency used in this experiment is experimental currency units (ECU). Participants completing the session do not risk losing any money. At the end of the experiment all your earnings will be converted to US Dollars. The conversion rate is $10 \mathrm{ECU}=1 \mathrm{US}$ Dollar. You will be paid in cash when you finish the experiment. The more ECU you earn, the more US Dollars you earn. If you participate in this experiment until the session is over, then you will be paid an additional 5 US Dollars.

Auction rules and calculation of earnings

You will be participating in 20 auctions. At the beginning of the first auction, you will be randomly matched with another participant in this room; every auction, you will be randomly re-matched with a different participant. In each auction you will be bidding against the participant with whom you are matched.

In a given auction, there is a fictitious good that is sold. When the first auction starts, you will observe your valuation of the fictitious good. Your valuation is a number between 50 and 100 and it is randomly selected from the [50,100] interval with equal probability and rounded to the nearest cent. The other bidder participating in this auction also receives his or her independent valuation for the fictitious good and his or her valuation is also randomly selected from $[50,100]$ interval. Each bidder will know only his or her own valuation.

The price for the fictitious good will start at 50 and will gradually increase to 60 , $70,80,90$, and 100. At price level 50, both you and your opponent are in the auction. Then the computer will randomly determine one of you as a provisional winner. Each bidder has $50 \%$ chance of being a provisional winner. Next, the computer will ask you if you would like to stay in the auction when the price increases to 60 . There are four possible things that can happen:

- You stay IN, your opponent stays OUT: Then you win the fictitious good and pay 60.

- You stay OUT, your opponent stays IN: Then your opponent wins the fictitious good and pays 60 .

- You stay OUT, your opponent stays OUT: Then the provisional winner wins the fictitious good and pays 50.

- You stay IN, your opponent stays IN: Then the price moves to the next level which is 70 .

If both you and your opponent stay in the auction for price level 60, then the computer will randomly determine a new provisional winner and ask if you would like to stay in the auction when the price increases to 70. Again there are four possible things that can happen:

- You stay IN, your opponent stays OUT: Then you win the fictitious good and pay 70 . 
- You stay OUT, your opponent stays IN: Then your opponent wins the fictitious good and pays 70 .

- You stay OUT, your opponent stays OUT: Then the provisional winner wins the fictitious good and pays 60.

- You stay IN, your opponent stays IN: Then the price moves to the next level which is 80 .

If both you and your opponent stay in the auction for price level 70, then the computer will randomly determine a new provisional winner and ask if you would like to stay in the auction when price increases to 80 .

The same procedure will repeat for price levels 90 and 100. If both of you are still in the auction when the price level is 100 , then the computer will randomly assign the fictitious good to one of the bidders with equal chance, and the winner will pay 100.

Please note that the price level only increases if both bidders stay in the auction. Each time the price level increases a new provisional winner is randomly determined by the computer and each bidder has equal chance of being the provisional winner at that price level. The provisional winner wins the fictitious good at the previous price level if both bidders stay OUT at the current price level. Otherwise, if one bidder stays in and the other bidder stays out in the current round, then the bidder who is IN wins the good at the current price, regardless of the provisional winner designation.

When one bidder wins the good, the auction is over. If you are the winner at a given price, then you earn the difference between your valuation and the price. For example, let us say you have a valuation of 82.55 for the fictitious good in the current auction and you win the good at a price of 60 . Then your earning from this round is

$$
\text { Earning }=82.55-60=22.55 \mathrm{ECU}
$$

When the first auction is completed, the second auction will start. At the beginning of the second auction, you will be randomly matched with another participant in this room and play with that person in this auction. First, the computer will show you your new valuation for the good for this auction. It is again a randomly selected number from $[50,100]$ interval. Your opponent will also observe his or her own valuation of the good for this auction privately. The same auction rules as in the first auction will apply.

There are 20 auctions in total. The computer will sum up your earnings in ECU in all auctions and convert this amount to US Dollars by dividing by 10 . We will pay you this amount in cash at the end of the experiment in person.

In order to make sure that you understand the rules of the auction, we have a test period before the real session starts. In this test period, you will see some multiple choice questions about the auction rules. Please answer those questions to the best of your knowledge. You may look at the hard copy of the instructions while answering them. Once you answer all the questions correctly, one practice auction will be conducted for which no payment will be made. Then the experiment will start with 20 real auctions.

Please ask if you have any questions.

Questions for the test period (asked to the subjects during the test period by the computer) 
(1) The price level just moved from 60 to 70 and the computer determined you as the provisional winner for the current price. The computer asks you if you would like to stay in for price level 70. You said that you are IN and your opponent said that he or she is OUT. Then what would be the outcome of the auction?

(a) Your opponent would win the good and pay 70 .

(b) You would win the good and pay 70.

(c) You would win the good and pay 60.

(d) Nobody would win the good and the price would move to 80 .

Answer: (b)

(2) The price level just moved from 60 to 70 and the computer determined your opponent as the provisional winner for the current price. The computer asks you if you would like to stay in for price level 70. You said that you are OUT and your opponent said that he or she is OUT. Then what would be the outcome of the auction?

(a) You would win the good and pay 70 .

(b) Your opponent would win the good and pay 70 .

(c) You would win the good and pay 60.

(d) Your opponent would win the good and pay 60.

Answer: (d)

(3) Your valuation of the good is 91 for the current auction. The price level just moved from 70 to 80 and the computer determined you as the provisional winner for the current price. The computer asks you if you would like to stay in for price level 80. You said that you are OUT and your opponent said that he or she is OUT. Then what would be your and your opponent's earnings for this auction?

(a) You would win the good and pay 70. You would earn 21 and your opponent would earn 0 .

(b) Your opponent would win the good and pay 70. You would earn 0 and you cannot know your opponent's earning without knowing his or her valuation.

(c) You would win the good and pay 80. You would earn 11 and your opponent would earn 0 .

(d) Your opponent would win the good and pay 80. You would earn 0 and your opponent would earn 15.

Answer: (a)

\section{References}

Ausubel LM, Cramton P (2004) Auctioning many divisible goods. J Eur Econ Assoc 2:480-493

Ausubel LM, Cramton P, Filiz-Ozbay E, Higgins N, Ozbay EY, Stocking A (2011) Common value auctions with liquidity needs: an experimental test of a troubled assets reverse auction. Working Paper, University of Maryland

Cox JC, Roberson B, Smith VL (1982) Theory and behavior of single object auctions. Res Exp Econ 2:1-43

Cox JC, Smith VL, Walker J (1988) Theory and individual behavior of first-price auctions. J Risk Uncertain 1:61-99

Cramton P, Filiz-Ozbay E, Ozbay EY, Sujarittanonta P (2012) Discrete clock auctions: an experimental study. Exp Econ 15(2):309-322 
Cramton P, Sujarittanonta P (2010) Pricing rule in a clock auction. Decis Anal 7:40-57

Delgado MR, Schotter A, Ozbay EY, Phelps EA (2008) Understanding overbidding: using the neural circuitry of reward to design economic auctions. Science 321:1849-1852

Engelbrecht-Wiggans R, Katok E (2008) Regret and feedback information in first-price sealed-bid auctions. Manag Sci 54:808-819

Filiz-Ozbay E, Ozbay EY (2007) Auctions with anticipated regret: theory and experiment. Am Econ Rev 97:1407-1418

Filiz-Ozbay E, Ozbay EY (2010) Anticipated loser regret in third price auctions. Econ Lett 107(2):217-219

Fischbacher U (2007) z-Tree: Zurich toolbox for ready-made economic experiments. Exp Econ 10(2): 171-178

Kagel JH (1995) Auctions: a survey of experimental research. In: Roth AE, Kagel JH (eds) Handbook of Experimental Economics. Princeton University Press, Princeton

Kagel JH, Levin D (1993) Independent private value auctions: bidder behaviour in first-, second-, and third-price auctions with varying numbers of bidders. Econ J 103:868-879

Kagel JH, Levin D (2008) Auctions: a survey of experimental research, 1995-2008. In: Roth AE, Kagel JH (eds) Handbook of Experimental Economics, vol 2. Princeton University Press, Princeton

Kinetz E (2010) India's 3G spectrum auction raises \$14.6 billion. The Associated Press, New York

Kőszegi B, Rabin M (2006) A model of reference-dependent preferences. Q J Econ 121:1133-1166

Lange A, Ratan A (2010) Multi-dimensional reference-dependent prefer-ences in sealed-bid auctions: how (most) laboratory experiments differ from the field. Games Econ Behav 68(2):634-645

Sugden R (2003) Reference-dependent subjective expected utility. J. Econ. Theory 111:172-191 